Pensamiento Crítico Vol. 19 № 1, pp. 105-113

\title{
Las megaganancias y la crisis financiera del 2008
}

The megaganacias and financial crisis of 2008

Víctor Orozco Livia*

\section{RESUMEN}

La voluminosas ganancias obtenidas por los conglomerados multinacionales a inicios de la primera década del 2000, generó un exceso de depósitos que los bancos norteamericanos no pudieron colocar, encontrándose en la disyuntiva de transgredir las normas de la regulación crediticia. Prestaron, entre otros, a insolventes que deseaban adquirir bienes inmuebles y estos ocasionaron una elevada tasa de morosidad. Al crearse activos financieros con garantías de cédulas hipotecarias "subprimes", que se difundieron en la banca mundial, estalló la crisis en el 2008, comprometiendo catastróficamente a bancos y empresas privadas, en dimensiones como lo ocurrido en 1929.

Palabras clave: elevadas ganancias, regulación crediticia, cédulas "subprime", tasa de morosidad, crisis financiera.

\section{ABSTRACT}

The voluminous profits from multinational conglomerates to the early 2000s, generated an excess of deposits that U.S. banks could not place, being in the dilemma of breaking the rules of the credit regulation. Lent, among others, who

* Economista y magíster en filosofía con mención en epistemología. Profesor principal en la Facultad de Ciencias Económicas 


\section{Pensamiento Crítico Vol. 19. N I}

wished to acquire insolvent property and these caused a high rate of default. When financial assets created with guaranteed mortgage bonds "subprime", which spread into the global banking crisis broke out in 2008, committing catastrophically banks and private companies, as happened in 1929 dimensions.

Keywords: Elevated earnings, credit control, debentures "subprime" default rate, financial crisis.

\section{El escenario de la crisis financiera}

El capitalismo fue en sus inicios competencia entre pequeñs y medianas empresas; luego en la segunda fase de su desarrollo, fue competencia entre corporaciones multinacionales. Hoy, y desde aproximadamente la década del 70, es competencia entre conglomerados multinacionales.

En la primera y segunda fase, las empresas contaron con una tecnología mecánica y en la tercera fase cuentan con tecnología cibernética.

Las grandes empresas que incorporaron la nueva tecnología arrasaron en el mercado a las de tecnología mecánica y las que no querían parecer, en estas nuevas condiciones, tuvieron que fusionarse, integrarse o hacer alianzas con las de tecnología de punta. Así aparecieron los conglomerados multinacionales. Es la imposición de los joint venture, que dio lugar a que un estudioso de la globalización expresara en 1993 que "hoy se necesita una estrategia total que incluya un componente de globalización y esa estrategia se encamina a manejar los negocios multinacionales en una forma mundialmente integrada, no como una federación de sucursales flojamente entrelazadas"(1).

La nueva tecnología incorporada a estas grandes empresas libera mano de obra generando desempleo, tal como puede apreciarse en el cuadro adjunto sobre desempleo y recesiones en EE. UU. El promedio de desempleo alcanza el $4.5 \%$, muy alto para una población de más de 300 millones de habitantes. Por consiguiente, a menores costos laborales mayor ganancia.

1 Yip George. "Globalización. Ed. Norma. Botota, 1993. Pág. XIII. 


\section{Víctor Orozco Livia}

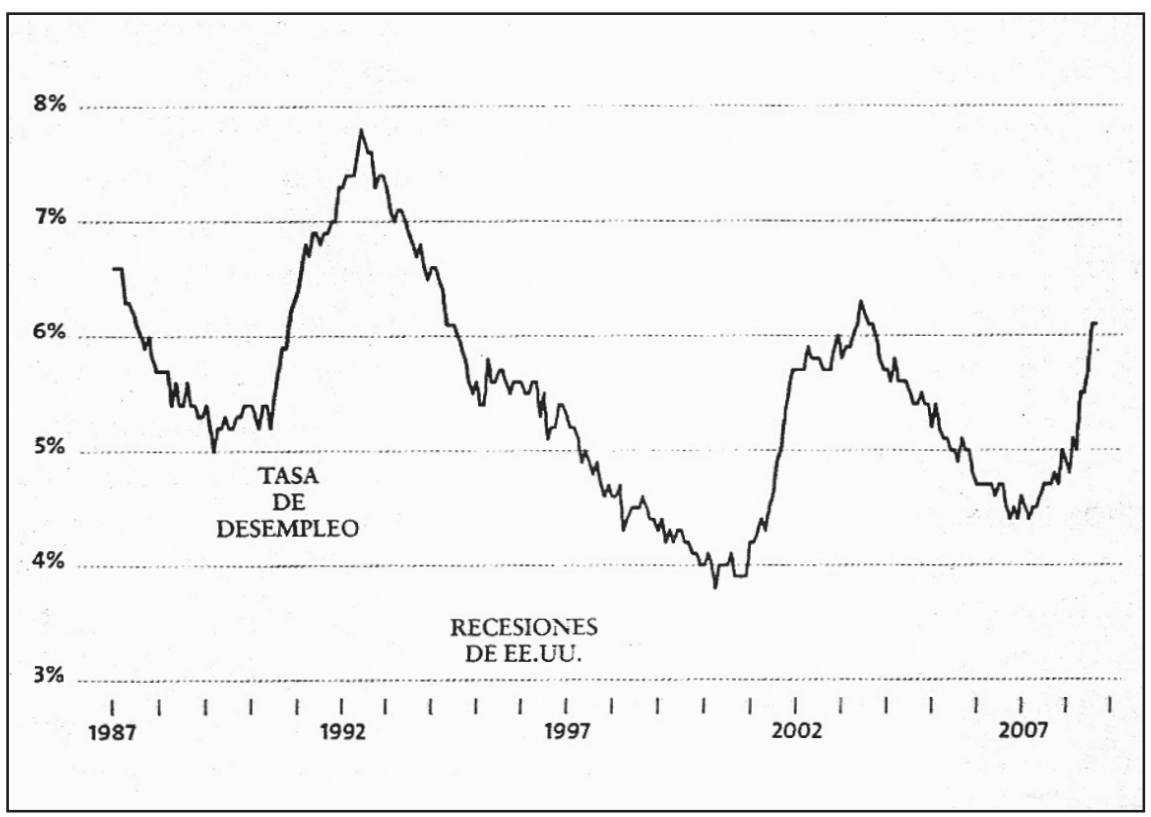

Fuente: Krugman P. Economía de la depresión. Pag. 151

\section{El descenso del costo financiero}

Alrededor de 160 crisis económicas ha experimentado la economía de mercado en la historia.

La que antecedió a la crisis financiera del 2008 fue la que se produjo en el 2001, conocida como crisis de dotcom, que hizo colapsar a empresas de internet. El Gobierno norteamericano y la Reserva Federal disminuyeron la tasa de interés en el 2002, de 6\% a 1\%, con la finalidad de remontar la crisis. Alrededor de 8,000 bancos norteamericanos se lanzaron a la colocación de créditos a empresarios y también a usuarios que mantenían ahorros irrisorios en sus cuentas de depósitos. Lo último significó una quiebra de las reglas de la regulación crediticia. Los empresarios fueron los más beneficiados con el dinero barato ya que las cédulas hipotecarias que dieron lugar a "default" no constituían un monto considerable, pero sí fue la mecha prendida que ardió hasta el estallido de la crisis. Como lo expresará Poal Marcet, "las subprimes son solo un 15 por ciento 


\section{Pensamiento Crítico Vol. 19. N I}

del mercado hipotecario en Estados Unidos, pero la «titulación` de las mismas estaba diseminada por todo el mercado financiero y mezclada con otros activos a través de fondos de inversión. Las agencias de rating no lo detectaron"(2).

La inyección de dinero barato al sector inmobiliario dinamizó a este sector, aumentó el precio de las viviendas y se elevó la cotización de los activos en la bolsa. Había una sensación de prosperidad por la tasa de interés baja y las familias incrementaron inusualmente sus adquisiciones al crédito. Ver cuadro sobre la deuda familiar en Estados Unidos. Como en 1929 la deuda familiar alcanzó un elevado nivel como porcentaje del PBI en el 2008, año del estallido de la crisis.

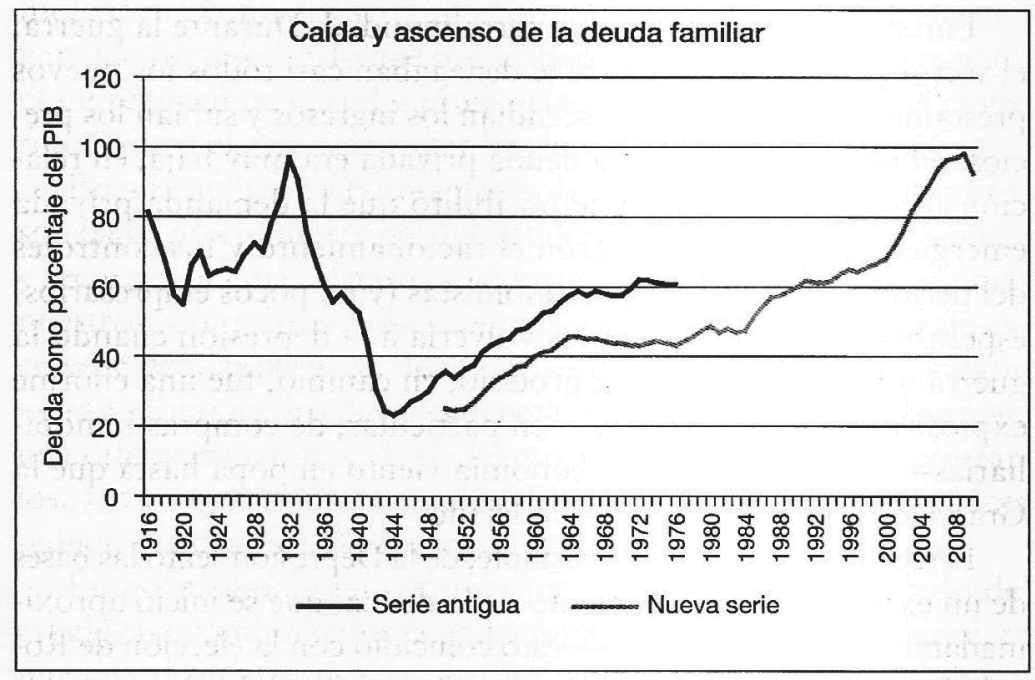

Fuente: Historical Statistics of the United States, Millenial Edition (Oxford University Press) y Junta de la Reserva Federal

Ante la incubación de una burbuja inmobiliaria por la especulación en los precios de las viviendas y la especulación en las cotizaciones en bolsa, la Reserva Federal aumentó la tasa de interés a un 3\% en el 2005 y hasta el $5.55 \%$ en el 2006, para desalentar los créditos. Los deudores en general quedaron afectados y en especial los firmantes

2 Marced, José Poal. iLlegó la criis! Ed. Granica. Barcelona 2008. Pág. 50. 


\section{Víctor Orozco Livia}

de las cédulas hipotecarias que incurrieron en "default" (incapacidad de pago) y la morosidad se hizo inmanejable. Los banqueros optaron entonces por la "titulación" de las cédulas hipotecarias incobrables, activos que, mezclados con otros activos saneados, se vendieron en la red bancaria mundial expandiendo la crisis a nivel internacional.

\section{El incremento de la productividad}

Desde que los hombres primitivos tomaron piedras para golpear y matar animales para el consumo de su carne, empezó el incremento de la productividad. La piedra en manos de esos hombres multiplicó la fuerza del golpe con el puño.

Tres revoluciones científico - tecnológicas que se han dado en la historia de la humanidad tendieron a elevar en cada caso la productividad.

En un artículo que publicó en Internet Jorge Sicilia, economista jefe de Norteamérica en el Servicio de Estados BBVA sobre la productividad en Estados Unidos, señala que de 1971 a 1991, época de difusión e implementación de la nueva tecnología cibernética en las grandes empresas conglomeradas, la productividad registró un promedio de $1.5 \%$ y desde que se consolidó la alianza de las multinacionales de 1995 al 2005 la productividad promedio alcanzó un 3.0\%. Después de un breve bajón por la crisis del 2008, la productividad en el 2013 se acercó al 3.0\%.

La nueva tecnología operada por los cognitarios que multiplican las energías mentales para crear los bienes y servicios que necesita la humanidad hoy en día no hace sino disminuir los costos de producción que en última instancia significa más ganancias.

\section{El neoliberalismo y la elevación de la tasa de explotación}

El neoliberalismo aparece a fines de la década del 70, como una respuesta norteamericana a los llamados gobiernos "populistas", sobre todo de Juan José Torres, de Bolivia. Juan Velasco Alvarado en Perú y Salvador Allende en Chile, fueron gobiernos que brindaron apoyo al desarrollo de empresas públicas y de capital nacional, disminuyeron la injerencia de la inversión extranjera e intentaron redistribuir ingresos a favor de las grandes mayorías de la población, propósitos que se contraponen a los del gran capital. 


\section{Pensamiento Crítico Vol. 19. N I}

El neoliberalismo es una propuesta de reducción de la participación del Estado en la economía, liberalización de los mercados internacionales y flexibilización del régimen laboral, en clara alusión a procurar mayores ganancias a los conglomerados internacionales.

Pretende ser el neoliberalismo un modelo de desarrollo para todos los países del mundo, pero los efectos de sus aplicaciones dicen lo contrario: favorece a unos cuantos y desfavorece a la gran población mundial.

Como propuesta de paradigma económico, el neoliberalismo posee tres ingredientes básicos: la filosofía neopositivista, el monetarismo y el "Consenso de Washington".

La filosofía neopositivista, entre sus criterios epistemológicos, considera que los objetos de conocimiento son los fenómenos, concepto acuñado por Kant, que afirmaba que solo puede conocerse el fenómeno, es decir la apariencia del objeto, mas no el noúmeno, es decir la esencia o contenido de las cosas o hechos. No obstante, es el contenido lo que determina el comportamiento de los hechos y no la forma ni la apariencia de los hechos. Esta es la razón por la cual las teorías convencionales no logran resolver la crisis originada en el 2008. El otro ingrediente es la teoría monetarista, que, entre otras medidas, recomienda la fijación del salario en un libre acuerdo entre el empresario y el trabajador, desestimando que la economía de mercado solo se preocupa por optimizar recursos para la ganancia y se desentiende del problema de las fuentes de trabajo para la población económicamente activa. En condiciones actuales de una gran oferta de trabajo y menor demanda, el salario tendería a niveles ínfimos y la ganancia se sobredimensionaría. Por ello el salario mínimo vital en muchos países es muy bajo. Y el tercer ingrediente es la propuesta política del Gobierno norteamericano, designado como "Consenso de Washington", que entre sus recomendaciones exige que se desregule el mercado del trabajo o se flexibilice el régimen laboral.

Es una recomendación de flexibilización regresiva de la jornada de las 8 horas, estabilidad laboral y bonificación por tiempo de servicios. Los efectos de aplicación de esta política en el propio Estados Unidos se reflejaron en el 2010 en la tasa de explotación del trabajo, que dio como resultado que en la distribución del ingreso el $88 \%$ corresponda a empresarios y solo el $1 \%$ para trabajadores, tal como se demuestra en el siguiente cuadro. 


\section{Víctor Orozco Livia}

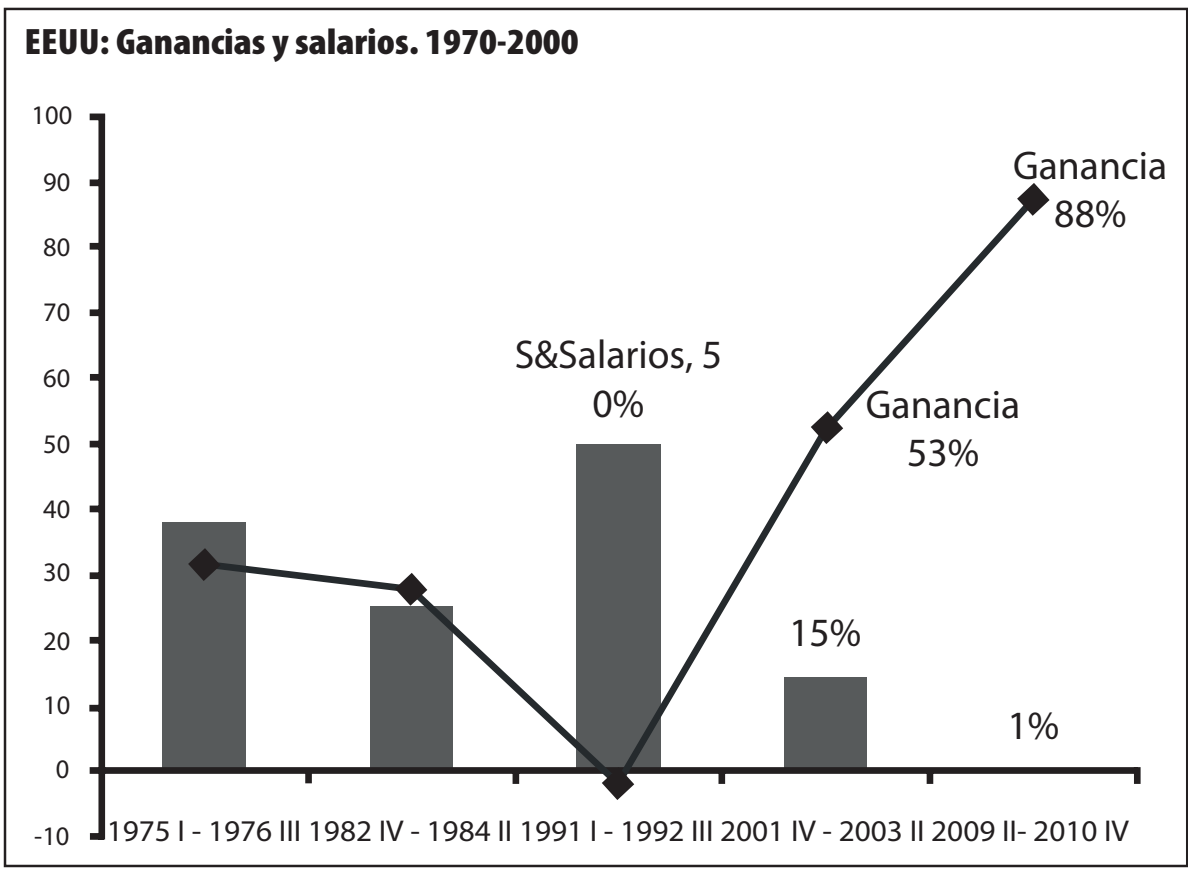

Fuente: Drum Kevin. Jun. 30, 2011. Reporte de investigación. Northeastern University’s Center for labor Market Studies.

\section{Las ganancias por la guerra en Irak}

Otro factor importante para el incremento de las meganancias fue la intervención bélica de Estados Unidos en Irak. Como dice Joseph Stiglitz, "estimamos que para Estados Unidos el costo económico y presupuestario estará en turno a los tres billones de dólares y para el resto del mundo quizá duplique esa cifra" (3). Son gastos que hizo el Estado norteamericano por compras a los proveedores para la guerra. Gastos en personal militar desplegado, armas sofisticadas de aire, mar y tierra, equipamiento militar, medicamentos, servicios de mantenimiento de sistemas de armamento, etc. que beneficia mayormente a las grandes empresas privadas. Fue una guerra injustificada por que la comisión nombrada por las Naciones Unidas no encontró pruebas sobre las acusaciones norteamericanas de que en Irak se fabricaba armas atómicas y químicas. Detrás de la guerra estaban los intereses los fabricantes de armamento bélico e intereses por el petróleo en Irak. Por eso

3 Stiglitz, J. La guerra de los tres billones de dólares. Ed. Taurus. México, 2008. Pág. 12. 


\section{Pensamiento Crítico Vol. 19. N I}

confirma Stiglitz que para "Llegar a la cifra de tres billones de dólares hemos tenido que mirar más allá de las malas prácticas presupuestarias del Gobierno y de su contabilidad engañosa. Puede parecer extraño decir esto, pero la guerra es un gran negocio" ( 4 ). El 19 de marzo de 2003, Estados Unidos y su "coalición de voluntad" irrumpieron en Irak y las enormes ganancias obtenidas por los conglomerados multinacionales se sumaron a las que dieron lugar por factores que ya se han visto.

\section{La sobreproducción de dinero y la crisis financiera}

La sobreproducción de la mercancía dinero por meganancias obtenidas por los conglomerados multinacionales constituyó la causa principal de la crisis financiera del 2008. Las dificultades de colocación de tales depósitos por los bancos los obligó a incurrir en transgresión de las normas de la regulación crediticia. Sutilmente lo admite así Steinberg cuando sostiene que "la crisis financieras internacional, causada por el exceso de liquidez y la inadecuada regulación de un sistema financiero internacional muy integrado, ha colocado a la economía mundial al borde de la recesión" ( 5 ). Si existe crisis en una rama económica, en este caso la financiera, arrastra a las demás ramas económicas por sus interrelaciones. Bancos y grandes empresas colapsaron cuando la oferta de dinero excedió largamente a la demanda. Ver cuadro sobre las ganancias en Estados Unidos.

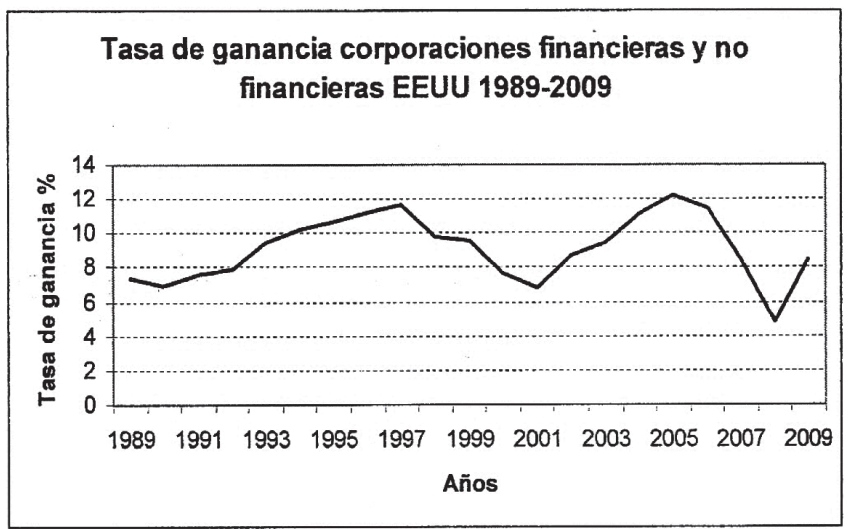

Fuente: Astarita Rolando. Buenos Aires, 2010. http://rolandoastarita.piles.wordpress.com

4 Stiglitz, J. Ob. Cit. Pág. 13.

5 Steinberg F. Causa y respuesta a la crisis financiera mundial. En la crisis económica mundial. Ed. La Queja negra. Ltda. México 2012. Pág. 155. 


\section{Víctor Orozco Livia}

En este cuadro estadístico de cálculo de la tasa de ganancias sobre los activos fijos, se puede notar que la tasa de ganancia de las corporaciones financieras y no financieras alcanzó un nivel ligeramente superior al $12 \%$ en el 2005, las más alta en dos décadas, decayendo después por la elevación de la tasa de morosidad de la "subprimes" y su impacto en la bolsa de valores y cotizaciones que desencadenó la crisis en el 2008.

\section{Referencias bibliográficas}

KRUGMAN P. 2009. El retorno de la economía de la depresión y la crisis actual. Ed. Crítica. Madrid.

STIGLITZ, J. 2010. Caída libre. Ed. Taurus. Madrid.

REINERT, E. 2007. La globalización de la pobreza. Ed. Crítica. Barcelona.

MARCOT P. M. 2008. iLlegó la crisis!. Ed. Granica. Barcelona.

DRUCKER P. F. 1993. La sociedad post capitalista. Ed. Norma Bogotá.

YIP. G. S. 1999. Globalización. Ed. Norma Colombia. 